\title{
DIAGNOSTIC DILEMMAS OF DISORDERS OF SEXUAL DEVELOPMENT - A SIX YEAR STUDY AT A PAEDIATRIC REFERRAL CENTRE.
}

M. Ramani1 ${ }^{1}$, O.H. Radhika Krishna², Kazi Wajid Husain³, K. Ramesh Reddy ${ }^{4}$, P. Sreenivasa Reddy ${ }^{5}$, S. Sai. Shreenika6, Puja Deshmukh77, G. Sunitha'.

\section{HOW TO CITE THIS ARTICLE:}

M. Ramani, O.H. Radhika Krishna, Kazi Wajid Husain, K. Ramesh Reddy, P. Sreenivasa Reddy, S. Sai. Shreenika, Puja Deshmukh, G. Sunitha. "Diagnostic dilemmas of disorders of sexual development - a six year study at a paediatric referral centre". Journal of Evolution of Medical and Dental Sciences 2013; Vol2, Issue 31, August 5; Page: 5909-5918.

ABSTRACT: BACKGROUND: Ambiguous genitalia are currently defined as disorders of sexual development (DSD) and constitute a complex, major social and medical emergency which is fortunately very rare. In developed countries, abnormalities of external genitalia occur in $1.7 \%$ of new born. Worldwide, approximately 1 in 2000 children are born with disorders of sexual development. Of all the causes, congenital adrenal hyperplasia remains the most common Aetiology. AIMS AND OBJECTIVES: The present study aims to analyse the various disorders of sexual development, their clinical presentation, histopathological findings and their treatment modalities. MATERIAL AND METHODS: The present study was undertaken at the Department of Pathology, Paediatric referral Hospital, Hyderabad from June 2004 to May 2009, eleven specimens were from children who presented with disorders of sexual development. Detailed case history was taken and all the results were reviewed. The specimens received included Gonadectomies and biopsies from gonads. The Haematoxylin and eosin stained slides were histologically evaluated. RESULTS: This study included a total of 11 children with disorders of sexual development, aged between 1 day and 9 years. Among them 7 were being reared as males, 3 as females, 1 as ambiguous. Out of 11 cases studied, 3 were diagnosed as male pseudo hermaphroditism, 1 female pseudo hermaphroditism, 1 male gonadal dysgenesis, 3 True hermaphroditism and 3 abnormal gonadal development. CONCLUSION: Histopathological confirmation of the gonadal sex plays an important role in the management of these children .There should be no change in sex beyond the second year of life. In the gender assignment, the gold standard is that genetic females should be reared as females. In genetic males, gender assignment is based on size of phallus. Early gender assignment \& precise diagnosis in disorders of sexual development is important. Surgical correction, hormonal supplementation and psychosocial management are the various treatment options available.

KEY WORDS: Disorders of sexual development (DSD), Ambiguous genitalia, Hermaphroditism, Gonadal dysgenesis, Gonads.

INTRODUCTION: Ambiguous genitalia are currently defined as disorders of sexual development (DSD) and constitute a complex, major, social and medical emergency which is fortunately very rare [1]. Harold Garfinkel in 1967 was the first sociologist to work on 'Intersexuality' using a method derived from sociological phenomenology which he called ethnomethodology. He based his analysis on the everyday common sense understanding of 'Agnes', a woman undergoing social and surgical gender reassignment [2]. 


\section{ORIGINAL ARTICLE}

In developed countries, abnormalities of external genitalia occur in $1.7 \%$ of new born. The prevalence of these disorders in most of the developing countries remains unknown. Globally, approximately 1 in 2000 children are born with disorders of sexual development [3].

Among the various problems encountered at birth, ambiguous genitalia remains one of the most distressing problem. Infants with DSD require multidisciplinary approach. Genital appearance has been quoted as an essential factor in childhood sex and psychosexual development [4].

Although the basic developmental events have long been known, the genetic, biochemical, endocrine, and molecular mechanisms are complex and have only been partially elucidated. The $\mathrm{H}-\mathrm{Y}$ antigen is understood to be the primary testis inducer. Other genes like SRY (Sex-determining region Y) gene and AMS gene have also been widely elucidated [5].

The complex interaction between genetic and endocrine processes during fetal development results in the appearance of the external genitalia. Ambiguous genitalia results from over-virilisation or masculinization of 46, XX female from androgen excess or under-virilisation or undermasculization of $46 \mathrm{XY}$ male due to disorder in androgen synthesis or action [3].Congenital adrenal hyperplasia (CAH) is the most common cause of female virilisation[6].

Although hormonal, genetic, molecular and radiographic investigations play an important role in diagnosis of the DSD, physical examination of the patient remains an important cornerstone for diagnosis [7].

The current study aims to analyse the various disorders of sexual development, their clinical presentation, histopathological findings and their treatment modalities.

MATERIAL AND METHODS: The present study was undertaken at the Department of Pathology, Paediatric referral Hospital from June 2004 to May 2009.We received a total of 2992 Paediatric surgical specimens and among these eleven specimens were from children who presented with disorders of sexual development. Detailed case history was taken for each case, physical examination was performed. Routine laboratory investigations, histological and radiological examination were done and all the results were reviewed. The specimens received included gonadectomies and biopsies from gonads. The Haematoxylin and eosin stained slides were histologically evaluated. Based on histopathological examination, all the 11 cases were further divided into various categories.

RESULTS: In this present study we reviewed a total of 11 children with disorders of sexual development, aged at presentation between 1 day and 9 years. Among them 7 were being reared as males, 3 as females, 1 as ambiguous (Chart 1 ).

Based on findings, the cases were diagnosed and categorized into 5 categories (Table 2).

Of 11 cases, 7 cases presented as phenotypically male with clinical presentation (Table 3). 3 cases presented as phenotypically female with virilised external genitalia, while only one of them showed ambiguous genitalia (Table 4).

After investigations, 3 children were diagnosed to have male pseudo hermaphroditism, 1 female pseudohermaphroditism, 3 true hermaphroditism, 3 abnormal gonadal development and 1 showed gonadal dysgenesis (Table 1, 2).

Cases 1, 2 and 3 were diagnosed to have Male pseudohermaphroditism. 


\section{ORIGINAL ARTICLE}

CASE 1: A 9 year old female child presented with virilised external genitalia and bilateral inguinal swelling. The inguinal swellings were resected on histology; fibrocollagenous tissue and normal epididymis were found. Seminiferous tubules were not seen.

CASE 2: A 6 year female child presented with virilised external genitalia and bilateral inguinal swelling. On histopathological examination, ovary, follicles, fallopian tubes, endocervix, epididymis along with mullerian duct remnants were detected. The child was diagnosed to have ovotestis (Figure 1).

CASE 3: A case of male pseudohermaphroditism in which a 9 year old child presented with left inguinal mass of 10 months duration, A bilateral Gonadectomy was performed. The left testis measured $4 \times 1.5 \times 0.8 \mathrm{~cm}$ while the right testis measured $3 \times 1.5 \times 0.5 \mathrm{~cm}$. On ultrasound examination ovaries and uterus were not visualized. Undescended bilateral testes were found in both the inguinal regions. The child was diagnosed as androgen insensitivity syndrome.

Cases 4, 5 and 6 were diagnosed as True hermaphroditism.

CASE 4: An 8 year old boy presented with bilateral undescended testis, chordae and hypospadias. On ultra sound examination, a rudimentary uterus on the left side and an undescended normal testis along with hydrocolpos were detected on the right side He was diagnosed as a case of true hermaphroditism. He underwent laparoscopic excision of the rudimentary uterus. Right orchidopexy and chordate correction were also performed. (Figure 2, 3).

CASE 5: An 8 year old male child presented with hypospadias and right inguinal swelling. Biopsy of gonads was performed. On exploration of the right inguinal region, mullerian duct remnants were detected (Figure 4).

CASE 6: A 9 year old boy presented with inguinal swelling. Right testis was non-palpable. Excision of the rudimentary gonads were performed. Microscopically, testes were found to be atrophic.

Cases 7, 8 and 9 were diagnosed to have abnormal gonadal development.

CASE 7: A 2 year old boy presented with bilateral undescended testis. On Ultra sound examination the right testis seen just below the inguinal ring measuring $2 \times 0.5 \times 0.1 \mathrm{~cm}$ while the left testis measured 1 x $0.5 \times 0.5 \mathrm{~cm}$. Uterus and ovaries were absent. Bilateral Gonadectomy, clitoris excision and labia minor reconstruction was performed.

CASE 8: An 8 year old boy presented with bilateral inguinal masses. Bilateral gonadal biopsy was performed. Para mesonephric ducts along with mullerian duct remnants were detected.

CASE 9: A 9 year old boy presented with bilateral inguinal masses. Left undescended testis was detected in the mid inguinal region. Microscopically testes were atrophic. Prominent stroma and tubular structures were detected. Gonadectomy was performed (Figure 5).

CASE 10: A case of female pseudohermaphroditism. 1 day old child presented with ambiguous genitalia. Labio scrotal folds were fused, clitoris was enlarged and gonads were non-palpable. Biopsy 


\section{ORIGINAL ARTICLE}

from gonads performed and measured $1 \times 0.5 \mathrm{~cm}$. Mullerian duct remnants and fallopian tubes were detected.

CASE 11: A case of Gonadal dysgenesis in which a 1 year old male child presented with left inguinal swelling. On ultrasound examination-rudimentary, streak gonads adjacent to bladder were detected on the left side (Figure 6).

DISCUSSION: Sexual differentiation is an orderly sequential process that begins with fertilization [8]. A defect at any level can lead to sexual ambiguity. Disorders affecting the end-organ androgen receptor are referred to as the androgen insensitivity syndrome (AIS) [9].

Disorders of sexual development can be classified into [10]:1. Female pseudohermaphroditism; 2. Male pseudo-hermaphroditism; 3. True hermaphroditism; 4. Asymmetrical gonadal dysgenesis. While aetiologically [11], patients with DSD can be classified into 3 categories which include Sex chromosome DSD, 46 XY DSD and 46 XX DSD.

Clinical assessment of DSD should include the history of drug intake in pregnancy and physical examination. The specific etiological diagnosis can be achieved by the appropriate hormonal investigations. A definitive diagnosis is also based on tissue receptor studies. However the exact determinants of gender identity still remain relatively unknown [12].Clinical management of DSD is controversial because the available evidence is limited and contradictory, with no long-term population based studies comparing matched controls [13].

In this present study we reviewed a total of 11 children with DSD, aged at presentation between 1 day and 9 years. Among them 7 (63\%) were being reared as males, 3 (27\%) as females, 1 $(1 \%)$ as ambiguous.

In a study by Rajendran et al. (1995)[14] which included 35 children with DSD, 2 were neonates, 19 were in the age group between 1 month and 2 years, nine between 2 and 5 years and 5 between 5 and 15 years.

Dessouky (2001) [15 ] evaluated 314 patients with DSD. At the time of presentation, 166 were reared as males and 148 as females and about 98 cases were classified as misassigned.

Crawford et al. (2009) [16] evaluated 41 cases of disorders of sex development. The mean age of the patients at the time of study was $7.5 \pm 2.1$ years. There were 19 female and 22 male participants and most common diagnosis in females was CAH while mixed gonadal dysgenesis in males. While Osifo et al. (2009) [17] reviewed a total of 40 female children with congenital aberrations of external genitalia, aged between 3 months and 16 years. Commonest causes were CAH and female pseudo hermaphroditism.

Of the 11 patients in our study, the karyotype was 46XY in 10 patients while 46XX in only one patients. No abnormal karyotype was reported. In a series by Kulkarni et al. (2009)[18] among 58 children, $43(74.1 \%)$ and $10(17.2 \%)$ were raised as males and females respectively. The karyotype was 46XY in $45(77.6 \%)$ and 46XX in $12(20.7 \%)$.

Al-Mulhim et al. (2010) [7] reviewed 41 patients with ambiguous genitalia and reported 14 patients with 46, XX karyotype. 18 patients had 46XY karyotype. 3 patients presented with abnormal karyotype. The karyotype was uncertain in 6 patients. Jaja et al. (2011) ${ }^{[3]}$ reported 6 patients with ambiguous external genitalia with the age ranges from birth to 16 years. CAH was the commonest diagnosis. 


\section{ORIGINAL ARTICLE}

Erdogan et al. (2011) [11] reviewed 95 patients, 26 patients had sex chromosome DSD, 45 patients had 46, XY DSD and 24 patients had 46, XX DSD. Most common causes of DSDs were Turner's syndrome, CAH and AIS. Our study revealed that the most common DSD was male pseudohermaphroditism and true hermaphroditism. While in the studies by Rajendran et al. (1995) [14] and Gollu et al. (2007) [4] DSD were most commonly classified into Female pseudohermaphroditism. Studies by Dessouky (2001) [15] and Joshi et al. (2006)[1] reported male pseudohermaphroditism to be the commonest DSD(Table 5)

CONCLUSION: Histopathological confirmation of the gonadal sex plays an significant role in the patients with disorders of sexual development. There should be no change in sex beyond the second year of life. In the gender assignment, the gold standard is that genetic females should be reared as females. In genetic males, gender assignment is based on size of phallus, if phallus is $<1.5 \mathrm{~cm}$ long , child should be reared as female. Early gender assignment and precise diagnosis in disorders of sexual development is important. Surgical correction, hormonal supplementation and psychosocial management are the various treatment options available. This study is an attempt made to throw light on the various disorders of sexual development so that early treatment will be available to these children to avoid the unnecessary discrimination and humiliation and gender identity disorders.

\section{REFERENCES}

1. Joshi RR, Rao S, Desai M. Etiology and clinical profile of ambiguous genitalia an overview of 10 years' experience. Indian Pediatr. 2006 Nov; 43(11):974-9.

2. Lucia Ruggerone, The Reflexive Order Of Language And Activities: Second Thoughts On Garfinkel's Ethnomethodology, International Journal of Sociology and Social Policy, 1996, Vol. 16 Iss: 4, pp.91 - 102.

3. Jaja T, Yarhere I, Anochie IC, Ambiguous External Genitalia in Childhood in Port Harcourt, Nigeria. Pediatr Therapeut.2011, 1:106.

4. Göllü G, Yildiz RV, Bingol-Kologlu M, Yagmurlu A, Senyücel MF, Aktug T, Gökcora IH, Dindar H. Ambiguous genitalia: an overview of 17 years' experience. J Pediatr Surg. 2007 May; 42(5):840-4.

5. Dreger AD. A history of intersexuality: from the age of gonads to the age of consent. J Clin Ethics. 1998 winter; 9(4):345-55. Review.

6. Ogilvy-Stuart AL, Brain CE. Early assessment of ambiguous genitalia. Arch Dis Child. 2004 May; 89(5):401-7.

7. Al-Mulhim AN, Kamal HM. Ambiguous genitalia in neonates: a 4-year prospective study in a localized area. East Mediterr Health J. 2010 Feb; 16(2):214-7.

8. A.A. Sinisi et al, Sexual differentiation, Journal of endocrinological investigation, 2003, 23-28.

9. Wisniewski AB, Migeon CJ, Meyer-Bahlburg HF, Gearhart JP, Berkovitz GD, Brown TR, Money J. Complete androgen insensitivity syndrome: long-term medical, surgical, and psychosexual outcome. J Clin Endocrinol Metab. 2000Aug; 85(8):2664-9.

10. Zdravković D, Milenković T, Sedlecki K, Guć-Sćekić M, Rajić V, Banićević M. Causes of ambiguous external genitalia in neonates. Srp Arh Celok Lek. 2001Mar-Apr; 129(3-4):57-60. 
11. Erdoğan S, Kara C, Uçaktürk A, Aydın M. Etiological classification and clinical assessment of children and adolescents with disorders of sex development. J Clin Res Pediatr Endocrinol. 2011; 3(2):77-83.

12. Coran AG, Polley TZ Jr. Surgical management of ambiguous genitalia in the infant and child. J Pediatr Surg. 1991 Jul; 26(7):812-20.

13. Warne G, Grover S, Hutson J, Sinclair A, Metcalfe S, Northam E, Freeman J; Murdoch Children's Research Institute Sex Study Group. A long-term outcome study of intersex conditions. J Pediatr Endocrinol Metab. 2005 Jun; 18(6):555-67.

14. RajendranR, Hariharan S. Profile of intersex children in south India. Indian Pediatr. 1995 Jun; 32(6):666-71.

15. Nabil M. Dessouky. Gender Assignment for Children with Intersex Problems: An Egyptian Perspective. Egyptian Journal of Surgery, April. 2001, Vol. (20), No. (2).

16. Crawford JM, Warne G, Grover S, South well BR, Hutson JM. Results from a pediatric surgical centre justify early intervention in disorders of sex development. J Pediatr Surg. 2009 Feb; 44(2):413-6.

17. Osifo OD, Amusan TI. Female children with ambiguous genitalia in awareness-poor subregion. Afr J Reprod Health. 2009 Dec; 13(4):129-36.

18. Ketan Prasad Kulkarni, Inusha Panigrahi, Reena Das, Surinder Kaur, Ram Kumar Marwaha. Pediatric disorders of sex development. The Indian Journal of Pediatrics. September 2009, Volume 76, Issue 9, pp 956-958.

TABLE 1: Table showing the Details of the Cases in our study.

\begin{tabular}{|l|l|l|l|l|}
\hline CASE & AGE & $\begin{array}{l}\text { LEGAL } \\
\text { KEX }\end{array}$ & KARYOTYPE & CLINICAL PRESENTATION \\
\hline 1 & 9 years & Female & $\mathrm{XY}$ & Virilized external genitalia with B/L inguinal swelling \\
\hline 2 & 6 Years & Female & $\mathrm{XY}$ & Virilized external genitalia with B/L inguinal swelling \\
\hline 3 & 9 Years & Female & $\mathrm{XY}$ & Left inguinal mass , Ambiguous external genitalia \\
\hline 4 & 8 Years & Male & $\mathrm{XY}$ & Bilateral undescended testes, chordae, hypospadias \\
\hline 5 & 8 Years & Male & $\mathrm{XY}$ & Hypospadias with Right inguinal swelling \\
\hline 6 & 9 Years & Male & $\mathrm{XY}$ & Inguinal swelling \\
\hline 7 & 2 Years & Male & $\mathrm{XY}$ & Bilateral undescended testes \\
\hline 8 & 8 Years & Male & $\mathrm{XY}$ & Bilateral inguinal masses \\
\hline 9 & 9 Years & Male & $\mathrm{XY}$ & Bilateral inguinal masses \\
\hline 10 & 1 day & $\begin{array}{l}\text { Male } \\
\text { Female }\end{array}$ & $\mathrm{XX}$ & $\begin{array}{l}\text { Ambiguous genitalia with fused labio-scrotal folds and } \\
\text { congenital Colon anomaly }\end{array}$ \\
\hline 11 & 1 year & Male & $\mathrm{XY}$ & Left inguinal mass \\
\hline
\end{tabular}


TABLE 2: Percentages of Different Categories of disorders of sexual development in our study.

\begin{tabular}{|l|l|l|}
\hline CATEGORY & NO. OF CASES & PERCENTAGE \\
\hline Male pseudo hermaphroditism & 3 & $27 \%$ \\
\hline Female pseudo hermaphroditism & 1 & $9 \%$ \\
\hline Abnormal gonadal development & 3 & $27 \%$ \\
\hline Gonadal dysgenesis & 1 & $9 \%$ \\
\hline True hermaphroditism & 3 & $27 \%$ \\
\hline
\end{tabular}

TABLE 3: Clinical Presentation of Male Children in our study.

\begin{tabular}{|l|l|l|}
\hline PHENOTYPICALLY MALE CHILDREN & NO. OF CASES & PERCENTAGE \\
\hline Inguinal swellings & $7 / 7$ & $100 \%$ \\
\hline Immature scrotal sac & $7 / 7$ & $100 \%$ \\
\hline Impalpable testis & $7 / 7$ & $100 \%$ \\
\hline Shortened phallus length & $3 / 7$ & $42 \%$ \\
\hline Hypospadias with or without chordae & $4 / 7$ & $57 \%$ \\
\hline
\end{tabular}

TABLE 4: Clinical Presentation of Female Children in our study.

\begin{tabular}{|l|l|l|}
\hline PHENOTYPICALLY FEMALE CHILDREN & NO. OF CASE & PERCENTAGE \\
\hline Virilised external genitalia & $3 / 3$ & $100 \%$ \\
\hline Ambiguous genitalia & $1 / 3$ & $33 \%$ \\
\hline
\end{tabular}

TABLE 5: Comparison of literature with our present study.

\begin{tabular}{|l|l|l|l|l|l|}
\hline $\begin{array}{l}\text { DISORDERS OF SEXUAL } \\
\text { DEVELOPMENT }\end{array}$ & $\begin{array}{l}\text { RAJENDRAN } \\
{[14] \text { et al. }}\end{array}$ & $\begin{array}{l}\text { DESSOUKY[15] } \\
\text { et al. }\end{array}$ & $\begin{array}{l}\text { JOSHI } \\
\text { [1] } \\
\text { et al. }\end{array}$ & $\begin{array}{l}\text { GOLLU } \\
\text { [4] } \\
\text { et al }\end{array}$ & $\begin{array}{l}\text { PRESENT } \\
\text { STUDY }\end{array}$ \\
\hline $\begin{array}{l}\text { Male } \\
\text { pseudohermaphroditism }\end{array}$ & $40 \%$ & $59 \%$ & $52 \%$ & $19 \%$ & $27 \%$ \\
\hline $\begin{array}{l}\text { True } \\
\text { pseudohermaphroditism }\end{array}$ & $14 \%$ & $6 \%$ & $2 \%$ & $6 \%$ & $27 \%$ \\
\hline $\begin{array}{l}\text { Female } \\
\text { pseudohermaphroditism }\end{array}$ & $46 \%$ & $26 \%$ & $28 \%$ & $60 \%$ & $9 \%$ \\
\hline Gonadal dysgenesis & $0 \%$ & $4 \%$ & $8 \%$ & $10 \%$ & $9 \%$ \\
\hline Others & $0 \%$ & $5 \%$ & $12 \%$ & $5 \%$ & $27 \%$ \\
\hline
\end{tabular}




\section{ORIGINAL ARTICLE}
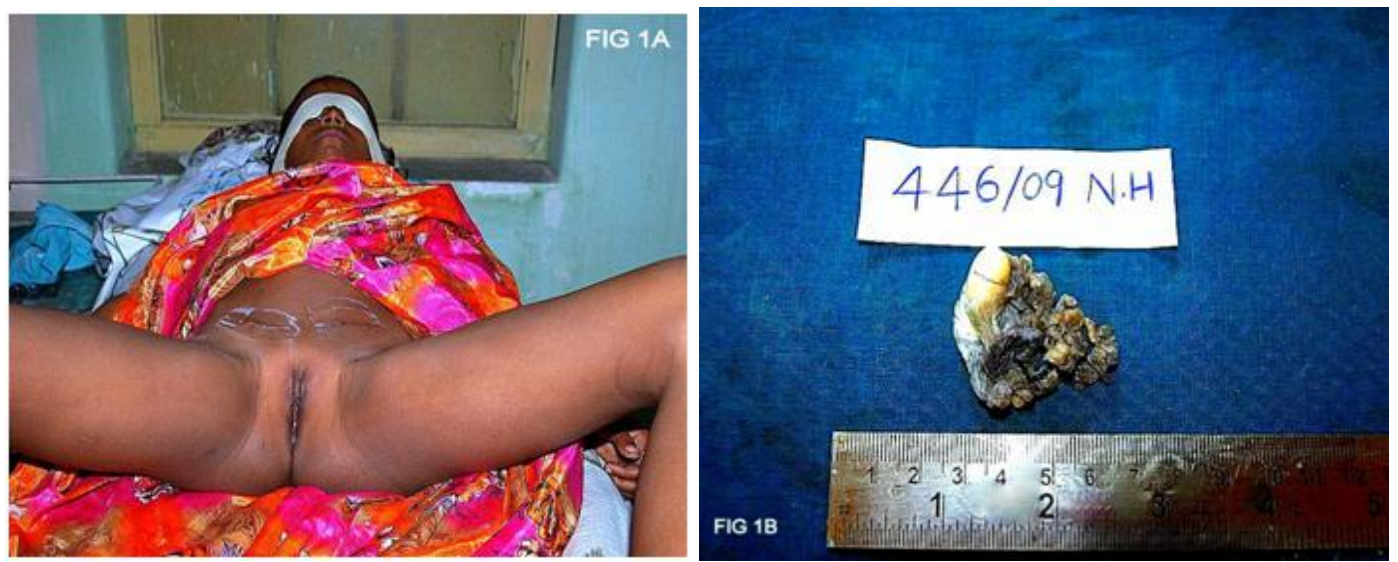

FIGURE 1: (A) Clinical picture of 6 year female child with male pseudo hermaphroditism. (B) Gross picture of Gonadectomy specimen.
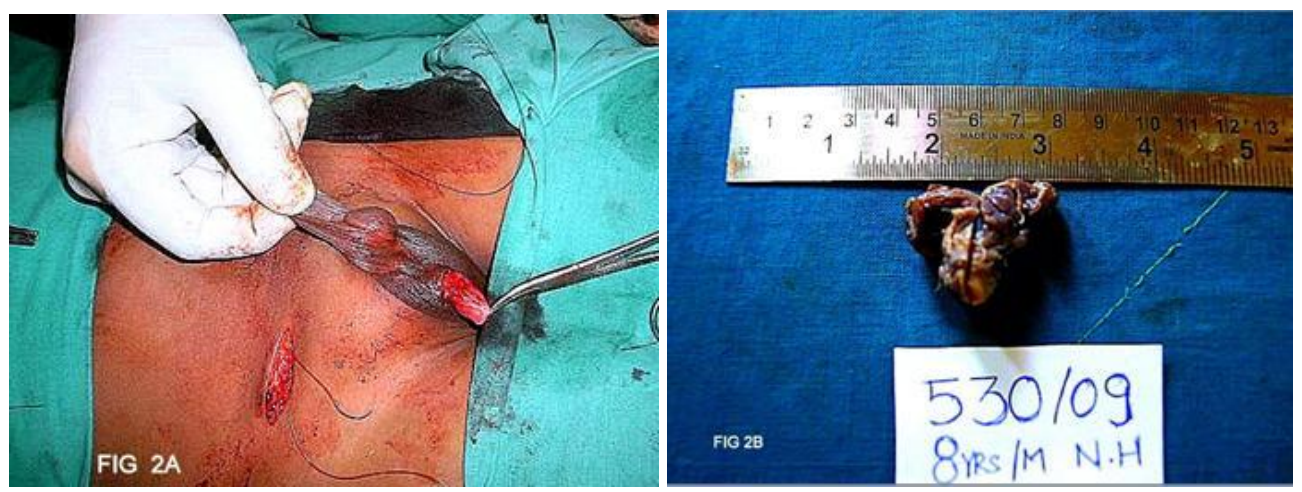

FIGURE 2: (A) A case of true hermaphroditism in 8 year male child (B) Grossly Gonadectomy specimen shows gray white-gray brown soft tissue mass measuring $5 \times 4 \times 2 \mathrm{~cm}$.

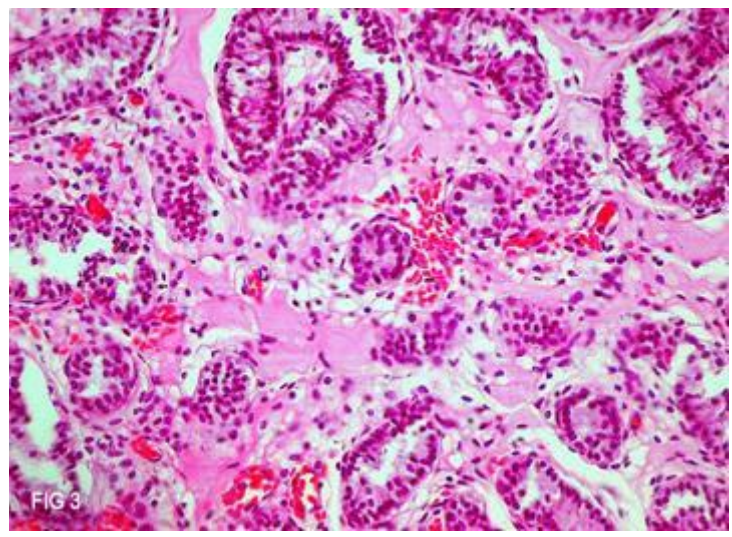

FIGURE 3: Photomicrograph shows structure of endometrium, cervix and atrophic seminiferous tubules. 


\section{ORIGINAL ARTICLE}

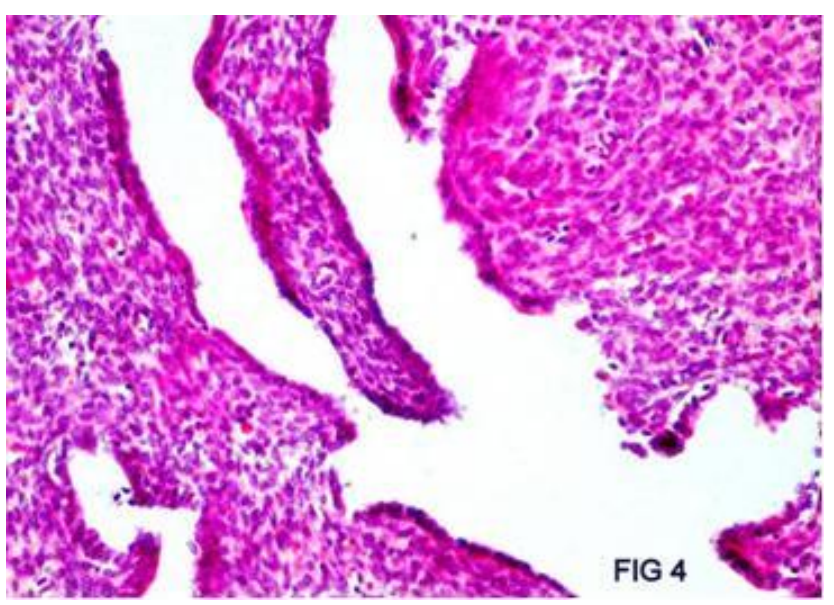

FIGURE 4: Photomicrograph shows remnants of Mullerian ducts (Haematoxylin and Eosin, 40X)

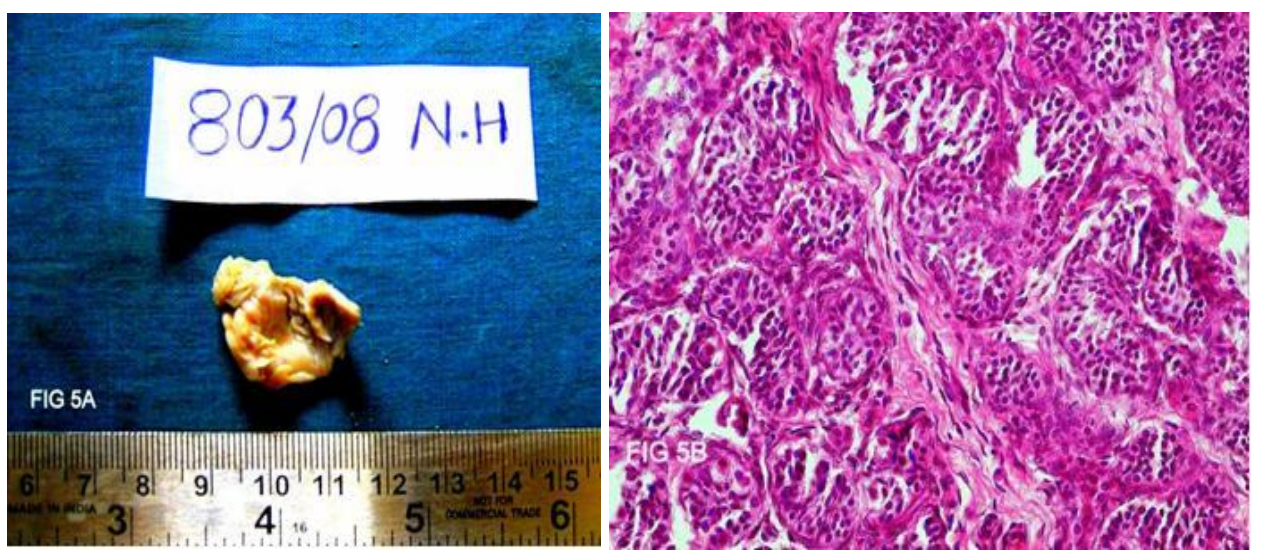

FIGURE 5: (A) Grossly Gonadectomy specimen, shows gray white soft tissue mass. (B) Photomicrograph shows seminiferous tubules(Haematoxylin and Eosin, 40X).

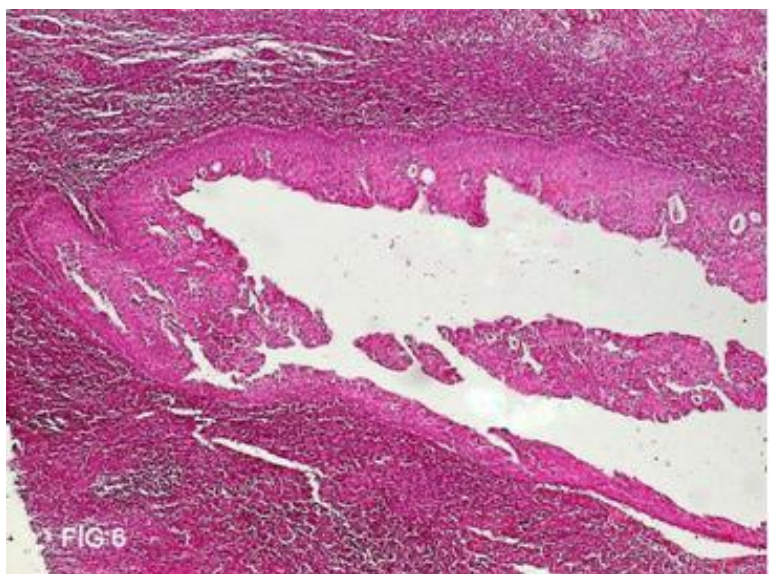

FIGURE 6: Photomicrograph shows loss of architecture and decreased seminiferous tubules (Haematoxylin and Eosin, 10X).

\section{CHARTS:}




\section{ORIGINAL ARTICLE}

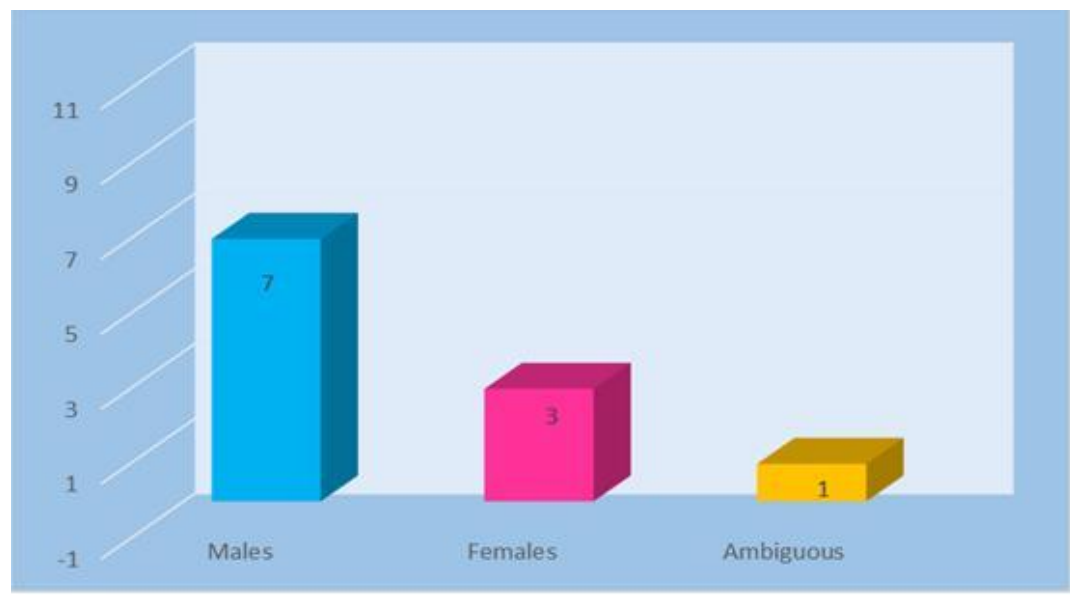

CHART 1: Phenotypical proportions of disorders of sexual development reviewed in our study.

\section{AUTHORS:}

1. M. Ramani

2. O. H.Radhika Krishna

3. Kazi Wajid Husain

4. K. Ramesh Reddy

5. P. Sreenivasa Reddy

6. S. Sai. Shreenika

7. Puja Deshmukh

8. G. Sunitha

\section{PARTICULARS OF CONTRIBUTORS:}

1. Professor. Department Of Pathology, Niloufer Hospital, Hyderabad.

2. Assistant Professor, Department of Pathology, Niloufer Hospital, Hyderabad.

3. Post Graduate, Department Of Pathology, Niloufer Hospital, Hyderabad.

4. Professor and H.O.D, Department of Paediatric Surgery, Niloufer Hospital, Hyderabad.

5. Assistant Professor, Department of Paediatric Surgery, Niloufer Hospital, Hyderabad.
6. Undergraduate, Third Year M.B.B.S, Osmania Medical College, Hyderabad.

7. Post Graduate, Department Of Pathology, Niloufer Hospital, Hyderabad.

8. Post Graduate, Department Of Pathology, Niloufer Hospital, Hyderabad.

\section{NAME ADDRESS EMAIL ID OF THE CORRESPONDING AUTHOR:}

Dr. M. Ramani,

Professor, Department of Pathology, Niloufer Hospital, Institute Of Child Health, Andhra Pradesh, Hyderabad, India.

Email : drmramani@sify.com

Date of Submission: 30/06/2013.

Date of Peer Review: 01/07/2013.

Date of Acceptance: 09/07/2013.

Date of Publishing: 05/08/2013 